\title{
Agôn
}

Revue des arts de la scène

Critiques | Saison 2010-2011

\section{Tempête dans un verre de petite eau}

Prix Europe pour le théâtre, Saint-Pétersbourg, du 12 au 17 avril 2011.

\section{Alice Carré}

\section{Q OpenEdition}

Journals

Édition électronique

URL : http://journals.openedition.org/agon/1679

DOI : 10.4000/agon.1679

ISSN : 1961-8581

Éditeur

Association Agôn

Référence électronique

Alice Carré, "Tempête dans un verre de petite eau », Agôn [En ligne], Critiques, mis en ligne le 01 mai 2011, consulté le 23 septembre 2020. URL : http://journals.openedition.org/agon/1679 ; DOI : https:// doi.org/10.4000/agon.1679

Ce document a été généré automatiquement le 23 septembre 2020

Association Agôn et les auteurs des articles 


\section{Tempête dans un verre de petite eau}

Prix Europe pour le théâtre, Saint-Pétersbourg, du 12 au 17 avril 2011.

\section{Alice Carré}

\section{RÉFÉRENCE}

Moscou-Petushki adapté du roman de Venedict Yerofeyev, Mise en scène d'Andriy

Zholdak

1 Dans sa tentative d'adapter le roman de Venedict Yerofeyev Moscou-Petushki, célèbre en Russie et traduit en français par le titre évocateur de Moscou-sur-Vodka, le metteur en scène ukrainien Andriy Zholdak se heurte à deux difficultés : la familiarité d'un roman dont les mots crus firent scandale lors de sa parution en 1969 et son aspect éminemment politique, puisque l'œuvre fût immédiatement interdite par le régime soviétique et circula longtemps comme samizdat, œuvres publiées clandestinement et diffusées sous le manteau. Le héros, sorte de double dégradé de l'auteur, quitte Moscou dans un état d'ivresse avancé afin de rejoindre Petushki, petite ville de banlieue où vivent sa maîtresse et son fils, utopie parodique renfermant l'espoir d'un monde meilleur. Le metteur en scène, qui, suite à des spectacles qui ont fait scandale, s'est fait connaître et reconnaître en Russie et en Europe de l'est, semble incapable d'opérer des choix et cherche autant à transposer la vision polémique de l'œuvre que son aspect onirique émanant des hallucinations du personnage. Il nous présente au bout du compte une œuvre excessive et vulgaire, qui manque de lisibilité et se traduit par un jeu outrancier. De bons comédiens dont Vladas Bagdonas, qu'on avait pu voir à l'odéon en Faust dans une mise en scène du lituanien Eimuntas Nekrosius, se trouvent livrés à eux-mêmes dans l'absence absolue de direction d'acteur, rendent compte de l'ébriété générale à grands renforts de hurlements.

2 Loin des délires éthyliques du héros en quête, sinon d'idéal, du moins de fuite, l'univers onirique proposé semble encore vulgaire tant les signes proposés manquent d'imagination. Les hallucinations sont traduites par des images sans finesse : indiens en costumes ridicules, apparition d'un Pouchkine à fausse barbe chantant d'une voix de 
stentor, ou de la femme aimée, évidemment de blanc vêtue. La scène, saturée d'objets, ne parvient pas à nous faire pénétrer dans l'univers intérieur de ce Don Quichotte moderne. Sans finesse sont aussi les signes du décor dont l'évidence déroute : l'échelle pointée vers le ciel, par laquelle Venedikt s'échappera au bout de son épopée, la maisonnette en bois représentant le foyer idéal de la maîtresse, et le chemin sinueux, à l'image du périple du héros. La scénographie travaille les angles aigus et les surfaces obliques pour illustrer la vision de l'homme ivre, mais aboutit à un usage aberrant de l'espace scénique, puisque les acteurs se trouvent compressés sur l'avant scène et que le fond de l'immense plateau est délaissé.

3 Le spectacle se mord la queue et suscite le même sentiment d'incompréhension chez le spectateur que chez le personnage ahuri. La mise en scène accentue l'aspect cyclique du roman, qui repose sur l'impossibilité de quitter Moscou, répétant des séquences deux fois, reprenant les mêmes phrases ou gestes. Pas d'issue possible, le train revient en gare de Moscou, et la ville de banlieue Petushki restera l'utopie fragile d'un monde sans rêves, à l'image de ce spectacle qui, malgré tous ses efforts, ne parviendra ni à restituer l'excès de ce texte, ni à faire rire la salle.

INDEX

Mots-clés : Moscou-Petushki, Yerofeyev (Venedict), Zholdak (Andriy), Prix Europe, SaintPétersbourg 